\title{
Ensino Remoto Emergencial: reflexões de um Núcleo de Educação a Distância
}

\author{
Patrícia Ribeiro Mattar Damiance ${ }^{1}$ \\ Stelamary Aparecida Despincieri Laham² \\ Mary Leiva de Faria ${ }^{3}$
}

\section{RESUMO}

Uma emergência de saúde pública de importância internacional desencadeou o Ensino Remoto em todo o mundo. Este estudo busca narrar a experiência de um Núcleo de Educação a Distância, na concepção e na execução do processo de transposição das aulas presenciais para aulas em mídias digitais, sob a ótica das fragilidades e das potencialidades que permearam o processo. Trata-se de um relato de experiência estruturado na relevância teórica, metodológica e política da documentação narrativa de experiências pedagógicas. A construção e a execução do plano de transposição das aulas atenderam à legislação vigente, apresentando pontos positivos e negativos e foi finalizada com depoimentos de aquisição de saberes e de recursos educativos valiosos para o aprendizado e para a prática pedagógica.

Palavras-chave: Ensino. Educação a Distância. Gestão Escolar. Prática de Ensino. Aprendizagem.

\footnotetext{
${ }^{1}$ patricia.mattar@alumni.usp.br - Fundação Educacional do Município de Assis (FEMA)

${ }^{2}$ stelamary@gmail.com - Fundação Educacional do Município de Assis (FEMA)

${ }^{3}$ ml.faria@uol.com.br - Fundação Educacional do Município de Assis (FEMA)
} 


\title{
Emergency Remote Teaching: reflections from a distance education core
}

\begin{abstract}
A public health emergency of international importance has triggered remote education around the world. This study seeks to describe the experience of a Distance Education Nucleus, in the conception and execution of the process of transposing face-to-face classes to classes in digital media, from the perspective of the weaknesses and potentialities that permeated the process. It is an experience report structured on the theoretical, methodological and political relevance of the narrative documentation of pedagogical experiences. The construction of the transposition plan for the classes complied with the current legislation, presenting positive and negative points and ended with testimonials for the acquisition of knowledge and valuable educational resources for learning and pedagogical practice.
\end{abstract}

Keywords: Teaching. Distance Education. School management. Teaching Practice. Learning. 


\section{INTRODUÇÃO}

Este trabalho fundamenta-se em reflexões sobre as potencialidades teóricas, metodológicas e políticas da documentação narrativa de experiências pedagógicas ou do relato de experiência. Este relato de experiência, quando elaborado por um ou mais membros da comunidade escolar, fomentou análises sobre questões relacionadas ao ensino, à aprendizagem, à gestão escolar, à pesquisa e à extensão, que podem ser planejadas e replanejadas para melhor atender ao público escolar. De maneira planejada ou não, a comunidade escolar constrói, na escola, diversas experiências carregadas de valor. É no espaço escolar que se materializa a prescrição do currículo e sua prática, na qual os atores escolares - docentes, alunos e pessoas ligadas à administração e ao apoio educacionais - criam sentido à aquisição de conhecimentos e à prática de ensino em determinado momento e lugar (SUÁREZ, 2011).

O autor supracitado ainda enfatiza que a relevância do relato está na forma do discurso, o qual deve se comunicar às experiências que se dão na escola, tais como o ensinar e o aprender; e não apenas isso: há que se atentar também para a narrativa das atividades extracurriculares, das reuniões entre os professores e dos movimentos em prol do ensino. As histórias devem ser narradas nas palavras dos autores, segundo suas sensações e ideias sobre o fenômeno analisado. Eis aí a razão da ênfase ao aspecto discursivo do ato de relatar algo. Essas histórias, de forma vital e prática, vêm demonstrar o que é o currículo em ação e o círculo da qualidade do ensino: "planejar, executar, documentar, analisar e redesenhar" (ZABALZA, 2009, p. 11).

A escrita reflexiva requer tempo e vontade do professor, bem como dos membros da comunidade escolar em compartilhar seus respectivos afazeres, suas tensões, limitações e situações interessantes construídas com seus pares. Nesse sentido, todos os sujeitos envolvidos no dia a dia da vida educacional acabam reinterpretando a prática gerencial e pedagógica. De outra parte, importa mencionar que uma das limitações de um relato de experiência consiste na capacidade e na competência dos autores em avaliar, criticamente, seu próprio desempenho, suas bases de ação e o contexto em que atuam. Essas habilidades e competências são pouco incentivadas nos currículos de formação inicial e pelas agências de apoio à pesquisa, que acabam por desmerecer estudos analíticos e comparativos sobre os processos de ensino (BARREIRO; GEBRAN, 2006).

Salienta-se que, de fato, todo relato traz contribuições e tem o poder de promover ideias e uma visão crítica sobre o ambiente escolar, o currículo e as práticas educativas em determinado momento sócio-histórico (SUÁREZ, 2011).

Diante dessa premissa, em um momento ímpar e recentíssimo para os sistemas de ensino do Brasil e do mundo, este estudo buscou descrever a experiência de participação da equipe de um Núcleo de Educação a Distância (NEaD) na concepção e execução do processo de transposição das aulas presenciais para aulas em mídias digitais, em uma Instituição de Ensino Superior (IES) de um 
município do Vale do Paranapanema, sob a ótica das fragilidades e das potencialidades que permearam o processo.

\section{A EXPERIÊNCIA: OS ALICERCES TEÓRICOS E O PROCESSO DE TRANSPOSIÇÃO DAS AULAS PRESENCIAIS PARA AS AULAS EM MÍDIAS DIGITAIS}

\subsection{O papel, as atribuições e os alicerces teóricos da equipe do núcleo de educação a distância}

Os Núcleos de Educação a Distância (NEaD) são estruturas administrativas responsáveis por decisões que vão desde uma iniciativa estratégica - como abertura de novos cursos ou definição de planos para expansão - até decisões de cunho operacional, como contratação de professores, preparação de material didático e suporte aos estudantes. Os Núcleos concentram todas as atividades que envolvem a operação da Educação a Distância (EaD), a saber: centrais de atendimento, suporte tecnológico, departamento financeiro entre outros. É o centro nervoso da EaD em uma IES. A necessidade da criação de um NEaD em uma instituição acontece quando esta já oferece cursos presenciais e deseja iniciar a oferta na modalidade a distância (BELLONI, 2015; BRASIL, 2018).

De acordo, ainda, com Brasil (2018), o Núcleo se configura como um órgão permanente de apoio da IES. Ele é responsável pelo planejamento, execução e acompanhamento de todas as ações educacionais na modalidade a distância, tendo como principal objetivo: desenvolver e implementar projetos de educação, mediados por diferentes mídias, a fim de promover a disseminação do conhecimento da maneira mais ampla e democrática possível, contando com uma equipe multidisciplinar, a qual é constituída por profissionais habilitados nas diferentes competências inerentes ao processo de desenvolvimento de projetos de Educação a Distância. Essa equipe tem como função analisar, desenvolver, implementar, acompanhar e avaliar os programas educacionais lançados nessa modalidade. Tem como objetivo oferecer educação de forma distribuída e continuada, promovendo a autoaprendizagem, a aprendizagem significativa, ativa e colaborativa, suportadas pelo uso sistemático das ferramentas tecnológicas de informação e comunicação.

Tendo em vista a oferta de EaD, Belloni (2015) classifica as instituições que trabalham tal modalidade como especializadas, ou singlemode; instituições integradas, ou dual-mode; e organizações pautadas em associações, redes ou consórcios - mixed-mode. As instituições singlemode oferecem puramente cursos a distância, como as Universidades Abertas. A denominação mixed-mode é caracterizada por consórcios de instituições, por exemplo, o que acontece no Brasil com o consócio CEDERJ, dentre outros. Nas instituições dual-mode, há os sistemas mistos, ou seja, presenciais e a distância. 
Para Nascimento (2014), os sistemas mistos, geralmente, apresentam vantagens em relação aos outros modelos, porque ambas as modalidades se beneficiam de forma mútua, trazendo benefícios acadêmicos e institucionais a todos os envolvidos no processo educativo. Além disso, segundo essa mesma autora, as instituições dual-mode, ou de sistemas mistos, em sua maioria, gozam de vasto prestígio e credibilidade no campo acadêmico e, por conseguinte, apresentam facilidades no desenvolvimento de programas e projetos em EaD.

A instituição objeto deste estudo é, na verdade, uma IES com 30 anos de experiência em cursos presenciais, os quais são reconhecidos pela comunidade local e regional, bem como pelos órgãos credenciadores oficiais. Em 2019, ao optar pela oferta da modalidade EaD em seus cursos de graduação e na concepção de novos cursos de formação inicial e continuada, criou-se, então, o NEaD.

O histórico da EaD na IES é recente. As discussões para a implantação da modalidade de ensino na Instituição iniciaram-se em 2017/2018, e, em fevereiro de 2019, foram ofertadas algumas disciplinas híbridas, no curso de Licenciatura e Bacharelado em Química Industrial. Concomitantemente, alguns membros de uma recém-organizada equipe multidisciplinar começaram a desenvolver pequenas consultorias pedagógicas para os professores do Ensino Presencial. Essas consultorias consistiam em apresentar aos professores os recursos didáticos do Ambiente Virtual de Aprendizagem (AVA) em um movimento de formação continuada (FUNDAÇÃO EDUCACIONAL DO MUNICÍPIO DE ASSIS, 2018).

Desde que as atividades de Educação a Distância foram iniciadas na IES, a grande preocupação do modelo criado, inicialmente para oferta de disciplinas híbridas, foi a de enfatizar a troca de conhecimento e de experiências entre alunos e professores e dos alunos entre si, respeitando o ritmo de aprendizagem de cada estudante. Além disso, primou-se por oferecer a possibilidade de que os graduandos buscassem soluções para as suas dificuldades de forma individualizada e, ao mesmo tempo, compartilhassem e construíssem conhecimentos.

Com o advento do Ensino Remoto, devido à pandemia do novo coronavírus, reflexões sobre o papel do NEaD na IES intensificaram-se entre o corpo diretivo da instituição em pauta e os membros do Núcleo. Tanto na visão da direção institucional quanto para os componentes do NEaD, o Núcleo é a unidade gestora responsável pela modalidade $\mathrm{EaD}$ da instituição, devendo promover a articulação com os cursos presenciais já oferecidos e buscar estratégias de superação do processo lento e frágil de reconhecimento institucional dessa modalidade (ARRUDA, 2018). Esse autor salienta para o fato de que a criação de um núcleo, com visão exclusiva para a modalidade remota, pode setorizar a oferta de EaD, o que neutraliza a tal modalidade, pois fortalece a separação entre presencial e a distância. Dessa forma, é necessário promover discussões sobre a indissociabilidade das modalidades e entre ensino, pesquisa e extensão.

Nesse contexto, o NEaD da IES tem trazido à pauta de suas discussões e pesquisas, principalmente na atual conjuntura, questões que valorizem uma educação em que as modalidades 
se estruturem de maneira mútua, de forma que não mais haja uma distinção entre os ensinos presencial e a distância, ou que se priorize um em detrimento do outro. É importante salientar que mais do que utilizar a tecnologia digital e organizar as aulas por meio da Educação a Distância, é necessária uma mudança de enfoque do problema que ora se impõe. Nas palavras de Moreira e Schlemmer (2020, p. 25), trata-se de uma mudança na educação para o que designam paradigma Onlife, em que se defende o fim da distinção entre o off-line e o on-line, no sentido em que as tecnologias digitais não sejam vistas apenas como instrumentos, mas, sim, como forças ambientais, as quais, cada vez mais afetam a consciência de nós mesmos, a forma como nos socializamos, interagimos e aprendemos, ou seja, "[...] a nossa concepção de realidade e as nossas interações com a realidade".

Em relação ao processo de ensino e de aprendizagem, a equipe do NeaD discute e compartilha o conceito de Moore (2002) sobre "distância transacional". Esta se apresenta como uma barreira psicológica que pode estar presente tanto na modalidade presencial quanto no Ensino a Distância. Tal conceito está relacionado ao grau de interação e interatividade entre os agentes do processo, uma vez que influencia a comunicação e o comportamento, apresentando-se como uma dificuldade que precisa ser transposta para que haja a efetiva construção de conhecimento. 0 grau de intensidade da distância transacional dependerá das metodologias adotadas pelos cursos, as quais devem ser combinadas com a complexidade comportamental das interações sociais e o grau de autonomia do estudante.

A equipe do Núcleo impregna seus processos de trabalho e suas consultorias com a ideia de que a educação deve ser vista como uma prática essencialmente social, na qual o professor deve transpor as barreiras geradas pela separação geográfica e alcançar todos os estudantes, de maneira a construir um espaço psicopedagógico propício ao desenvolvimento cognitivo e, por consequência, à diminuição da distância transacional.

\subsection{A construção da proposta e do plano de transposição das aulas presenciais para aulas em mídias digitais}

A equipe diretiva da IES do Vale do Paranapanema decidiu suspender as atividades acadêmicas presenciais, a partir de 17 de março de 2020, em atendimento às normativas e às regulamentações do Ministério da Saúde - Portaria n 356 de 11/03/2020 e Lei 13.979 de 06/02/2020 -, as quais estabeleceram as medidas e as ações para o enfrentamento da emergência de saúde pública de importância internacional, decorrente da COVID-19 (BRASIL, 2020a; 2020b).

Essa interrupção atendeu também ao Decreto do Governo do Estado de São Paulo n 64.862 de 13/03/2020, que tratou de medidas temporárias, de emergência e de prevenção do contágio pelo SARS-CoV-2, ou novo coronavírus. A decisão de suspensão das aulas presenciais por um período de 30 dias, sem prejuízo do calendário acadêmico, foi tomada em reunião da Congregação da IES, de forma unânime, no dia 17 de março de 2020 e contou com a presença dos coordenadores dos 11 cursos de graduação, bem como dos representantes dos alunos, dos professores e de outras esferas 
da instituição. Dessa forma, a partir do dia 23 de março de 2020, a instituição passou a oferecer "atividades acompanhadas" remotas, em substituição às aulas presenciais, cujos planos de ações, foram decididos pelo Núcleo Docente Estruturante (NDE) de cada curso, cada qual com sua especificidade (SÃO PAULO, 2020).

A partir das $12 \mathrm{~h}$ do dia 20 de março de 2020, todas as atividades relativas ao internato dos alunos do Curso de Medicina da instituição foram adiadas por um período de 30 dias. As atividades relativas aos estágios do Curso de Enfermagem foram realizadas até dia 25 de março, conforme a programação da coordenadoria do curso. As atividades relativas ao Projeto de Iniciação Científica (PIC) e ao Trabalho de Conclusão de Curso (TCC) foram mantidas e tiveram seu curso natural pelo contato remoto entre professores-orientadores e seus alunos-orientandos, com o cumprimento dos cronogramas de todos os cursos, inclusive.

As disciplinas híbridas do curso de Licenciatura e Bacharelado em Química Industrial também não sofreram alterações nos seus cronogramas e planos de ensino. A única alteração consistiu na transposição das aulas presenciais para aulas remotas síncronas e assíncronas, em mídias digitais, amparadas pela metodologia da sala de aula invertida (CHRISTIANSEN, 2014).

A suspensão das aulas presenciais, sem prejuízo do calendário acadêmico por meio da oferta das atividades acompanhadas e com a utilização de ferramentas tecnológicas disponíveis na instituição, foi comunicada ao Conselho Estadual de Educação (CEE) em 27 de março de 2020. As atividades acompanhadas, oferecidas virtual e sincronicamente, transcorreram em perfeita consonância com as portarias do Ministério da Educação (MEC) n 343/2020, de 17/03/2020, e n 345/2020, de 19/03/2020, bem como com a deliberação do Conselho Estadual de Educação (CEE) $177 / 2020$, de 18/03/2020. Dessa forma, as aulas de laboratório e as práticas de estágio, que deveriam ser presenciais, também foram interrompidas até novas orientações (BRASIL, 2020c, 2020d; CONSELHO ESTADUAL DE EDUCAÇÃO, 2020a).

O Modular Object-Oriented Dynamic Learning Environment (Moodle) foi o software educacional escolhido para o desenvolvimento das atividades acompanhadas, pois já era oferecido pela instituição. Grande parte dos professores não utilizava o software como apoio à aprendizagem, sendo necessário um trabalho maciço e conjunto das equipes de Tecnologia da Informação e do NEaD, que criaram muitas disciplinas, tutoriais de acesso e uso para professores e alunos.

Durante o período de suspensão de aulas presenciais e oferta de atividades acompanhadas, a equipe diretiva começou a pesquisar ferramentas tecnológicas que pudessem propiciar interação de forma síncrona entre professores e alunos. A primeira semana de atividades acompanhadas consistiu-se, basicamente, em postagens de arquivos e de slides. O professor deveria estar disponível via chat, no horário da aula, para tirar eventuais dúvidas. Em algumas disciplinas, houve a postagem de videoaulas elaboradas com captura de tela ou gravadas em programas de produção de slides, inclusive. 
Na primeira avaliação, o excesso de atividades postadas pelos professores gerou muita reclamação dos alunos. Estes, por sua vez, reconheceram o esforço docente e elogiaram a utilização de videoaulas por parte de alguns professores. Para o corpo discente, as aulas gravadas facilitavam o processo de aprendizagem, já que o professor, de forma assíncrona, estava explicando o conteúdo da disciplina e não simplesmente postando o conteúdo para o aluno estudar ou propondo a execução de trabalhos. Os estudantes relataram ainda que a entrega de tarefas ao mesmo tempo gerava um excesso de atividades cuja realização no prazo estipulado era algo impossível. Solicitaram aos coordenadores de curso o adiamento de datas de entrega e a utilização de videoaulas, as quais, para eles, resultavam em melhor compreensão do conteúdo. Nesse momento, um esforço maior para o desenvolvimento de atividades síncronas foi realizado pela Instituição e pelos professores. Vale destacar que a instituição ofereceu aos professores uma capacitação de conteúdos básicos do Moodle, e o NEaD propiciou tutoriais e assessorias individuais para a elaboração de videoaulas e atividades de ensino.

A criação de grupos de mensagens instantâneas, por meio do aplicativo WhatsApp, com a finalidade de comunicar atividades aos alunos se mostrou essencial para o desenrolar das atividades remotas. Na segunda semana de atividades acompanhadas, já de posse de outras ferramentas tecnológicas, alguns cursos optaram pela utilização do aplicativo Discord, uma plataforma de comunicação instantânea que permite a troca de mensagens em texto, áudio e vídeo; outros fizeram uso do Skype, software de comunicação em tempo real, ou seja, síncrono. Ao iniciar a utilização dessas tecnologias, alguns professores, em decorrência do tipo de conexão com a internet, não conseguiram o compartilhamento de tela pelo Discord, o que dificultou a utilização do mesmo em suas aulas. Nesses casos, lançaram mão da plataforma Zoom ou Google Meet. A partir de abril de 2020, o Programa Microsoft Teams foi adquirido pela instituição e indicado para o desenvolvimento das aulas síncronas.

Em meados de abril, com a comunicação síncrona bem estabelecida, alguns cursos já aplicavam provas bimestrais on-line. Muitos alunos começaram a criticar o tempo disponibilizado para a execução das avaliações, alegando problemas pessoais com as conexões de internet. Assim, o Conselho de Cursos decidiu que a duração da prova seria de $24 \mathrm{~h}$, em dia exclusivo para avaliação, priorizando a compatibilidade de agendas de avaliações das disciplinas e a de entrega de trabalhos acadêmicos.

Quanto à frequência escolar, o Conselho de Cursos decidiu que, caso o aluno não estivesse presente no encontro de forma síncrona, por algum problema com a conexão da internet, poderia acessar as videoaulas posteriormente; ao professor, foi facultada a possibilidade de marcar presença a esse aluno. Nesse momento, o Microsoft Teams já estava padronizado como plataforma de ensino institucional. Todos os alunos já acessavam o aplicativo da plataforma pelo computador e pelo celular. Os docentes, por sua vez, gravavam e disponibilizam as videoaulas, no Teams, e o link dessa gravação era copiado também para o AVA da disciplina, permitindo aos alunos assistir às aulas on-line em espaço-tempo assíncronos. Isso gerou maior satisfação e adesão do corpo discente às 
atividades acompanhadas, que seguiram em plataformas digitais até final do ano letivo, amparadas pela prorrogação do prazo do Decreto $n^{\circ} 64.862$, de 13 de março de 2020, e da criação das portarias do MEC nº 395/2020; n 473/2020 e n 544/2020 (BRASIL, 2020e, 2020f, 2020g; SÃO PAULO, 2020).

Cumpre salientar que, quando da passagem do primeiro para o segundo semestre de 2020, a IES passou a identificar a evasão escolar e o desestímulo dos alunos. Numa ação pontual de monitoramento ao desfalecimento discente, houve a indicação de uma maior proximidade e acolhimento dos coordenadores e professores junto ao alunado. Fez-se, então, a opção por uma espécie de flexibilização do currículo para o segundo semestre. Em um movimento coletivo, alguns professores e coordenadores iniciaram a reelaboração de planos de ensino, suprimindo e registrando, formalmente, os conteúdos programáticos que excederiam a capacidade de execução de forma remota, em especial, os conteúdos práticos. Noutros termos, priorizou-se o estritamente exequível em circunstâncias tão atípicas, como o são as de uma pandemia. A finalidade era a de estimular o aluno e fazer com que não abandonasse o sonho da graduação. Em consonância com a deliberação do CEE 185/2020, os cursos de Enfermagem e Fisioterapia da IES passaram a desenvolver atividades de estágio de forma remota: videoaulas, estudos de caso e de textos entre outros, não ultrapassando $30 \%$ da carga horária prevista para os estágios ou para o internato (CONSELHO ESTADUAL DE EDUCAÇÃO, 2020b).

A partir de agosto de 2020, com a liberação das atividades práticas para os cursos das áreas da saúde, em todas as fases do Plano São Paulo, o internato e o estágio curricular dos cursos de Enfermagem, Fisioterapia e Medicina, passaram a desenvolver, presencialmente, os componentes curriculares práticos. No caso do curso de Medicina, a partir de agosto, todas as atividades discentes transcorreram na modalidade presencial. Tal ação baseou-se, também, em Decreto Municipal e na adoção de protocolos sanitários rígidos como medida de segurança, com aulas sendo ministradas a pequenos grupos de alunos. No retorno às atividades presenciais, todos os professores e alunos dos cursos envolvidos foram submetidos a testes de anticorpos para o novo coronavírus e a ações expressas do Protocolo Instrutivo de Retorno às aulas presenciais da instituição.

Com relação às atividades de estágio do curso de Licenciatura em Química, adotou-se o que preconiza o Parecer do CEE n 109/2020, de 15/04/2020, tendo em vista que esse documento permite ao futuro professor cumprir, de maneira remota, as horas de estágio requeridas, utilizando-se de recursos digitais. Ocorre que as aulas no Ensino Fundamental e Médio, a essa época de pandemia, estavam, também, sendo ministradas a distância. Os professores de estágio entraram em contato com a supervisora de estágio da Diretoria de Ensino, que externou a impossibilidade de receber os estagiários naquele momento, pois a comunidade escolar estava em treinamento na plataforma virtual e se adaptando às novas formas de ensinar e aprender, não sabendo ao certo como as atividades remotas iriam ocorrer na rede estadual (CONSELHO ESTADUAL DE EDUCAÇÃO, 2020c).

Diante desse fato, a coordenadora e os professores de estágio, preocupados com os alunos do quarto ano da licenciatura, em vias de se formar, acessaram dois colégios privados de Ensino Médio do município do Vale do Paranapanema. Essas duas instituições permitiram o 
desenvolvimento das atividades de estágio dos alunos da Licenciatura de Química. Nos colégios, as atividades foram realizadas de forma remota pelas plataformas Google Meet e Zoom. O plano de estágio foi aprovado pelos colégios, os quais deram total apoio ao efetivo exercício da docência, vez que os alunos tiveram acesso às plataformas on-line em uso. Nessa etapa de estágio, o professor da disciplina, dentro do colégio, ficou responsável pela liberação do acesso e acompanhamento da presença do aluno estagiário às aulas, passando ao coordenador pedagógico a planilha de presença. 0 coordenador, por sua vez, tinha a incumbência de enviar essa planilha ao professor de estágio da IES. O professor da disciplina poderia solicitar auxílio do estagiário para colaborar com os alunos na resolução de exercícios, preparo de aulas e correções de atividades. Os alunos iniciaram as atividades de estágio em meados de junho e início de agosto e seguiram até dezembro de 2020.

No apoio às atividades de gestão escolar, foram disponibilizados aos alunos de estágio, do terceiro e quarto ano da Licenciatura em Química, via plataforma Moodle, os mesmos vídeos que estavam sendo apresentados às escolas estaduais para formação e aprimoramento docente.

Nas escolas da rede estadual, as atividades de estágio iniciaram-se em agosto de 2020. Os estagiários do terceiro e quartos anos acompanharam as aulas pela plataforma de compartilhamento de vídeos YouTube, pois não tiveram acesso ao Centro de Mídia do Estado de São Paulo. De forma geral, os alunos estagiários ajudaram em algumas atividades quando o professor solicitava. Essas atividades incluíam aulas de reforço, elaboração de questionário pelo Google Forms. Contudo, a participação dos futuros licenciados em Química, nessas atividades, não foi tão frequente quanto se esperava, já que os alunos do Ensino Médio não realizavam as atividades propostas. A pouca - ou nenhuma - adesão dos estudantes do Ensino Médio ao Ensino Remoto foi algo observado por diretores, supervisores de ensino, professores e pesquisadores de todo o país (DIAS; PINTO; 2020, PINHO, 2020; SILVA et al., 2020).

Naturalmente que isso resultou num entrave para as atividades de estágio; no entanto, foi possível promover a aprendizagem segundo o plano de ensino do estágio curricular, ou seja, a vivência da realidade das atividades remotas desenvolvidas durante a pandemia. Toda semana, via plataforma Teams, foram realizadas reuniões coordenadas pelas professoras responsáveis pelo estágio supervisionado, com vistas à formação e orientação dos estagiários. As docentes tiveram contato direto com as supervisoras dos estagiários, que atuavam nas escolas indicadas para essa ação.

Conforme o Parecer do CNE/CP n 05/2020, as instituições de educação superior podem adotar a substituição de aulas presenciais de laboratório por atividades não presenciais, desde que façam uso de um modelo de mediação de tecnologias digitais de informação e comunicação adequada à infraestrutura e interação necessárias. Segundo as determinações desse Parecer do $\mathrm{CNE} / \mathrm{CP}$, o Núcleo Docente Estruturante (NDE) do curso de Química deliberou que algumas aulas de Laboratório de Ensino de Química I e II poderiam ser ministradas de forma não presencial. Por outro lado, decidiu-se que as aulas de Laboratório de Ensino de Química III deveriam ser todas presenciais, 
visto que as atividades, nessa disciplina prática, envolvem competências e habilidades que o exigem. Estabeleceu-se, também, considerando a deliberação do CEE 185/2020, que as aulas não presenciais, realizadas de formas demonstrativas, não poderiam ultrapassar $30 \%$ da carga horária da disciplina (CONSELHO ESTADUAL DA EDUCAÇÃO, 2020b). As disciplinas de Laboratório de Ensino de Química I e II utilizaram, respectivamente, 30\% e 25\% da carga horária total para a realização de aulas demonstrativas.

Para o desenvolvimento das atividades práticas do curso de Direito, a coordenadoria do curso, em parceria com a Justiça Federal, criou um projeto que permitiu que os alunos dos $4^{\circ}$ e $5^{\circ}$ anos do curso participassem de audiências que aconteciam na Justiça Federal, na modalidade online, por meio do Google Meet. Essa ação contribuiu para a manutenção dos bons resultados de aprovação dos egressos do curso no exame da Ordem dos Advogados do Brasil/São Paulo (OAB), edição 2020 (FUNDAÇÃO EDUCACIONAL DO MUNÍCíPIO DE ASSIS, 2020).

Ao final do primeiro semestre e início do segundo semestre, o fenômeno da câmera fechada, por parte do alunado, tornava-se prevalente na IES. Os coordenadores de curso e professores manifestaram incômodo com o fenômeno e com os comportamentos discentes e docentes na internet. A equipe do NEaD, por intermédio da coordenadora e da designer gráfica, criou um infográfico com orientações sobre Regras de Netiqueta para reuniões e aulas on-line, com foco não apenas na etiqueta, mas também nos conceitos de distância, presença e interatividade, dentro do contexto do processo educativo (LAHAM; CONSTANTINO, 2020).

Nesse momento também, os cursos começaram a oferecer Webinários e lives direcionados aos alunos e abertos à comunidade, com assuntos relacionados aos conteúdos de cada curso, mas, também, relacionados à atualidade, tendo transmissão pelo canal do YouTube e pelas redes sociais da IES, tais como o Instagram. Os Webinários e as lives, com foco nos interesses da comunidade, se configuraram numa estratégia institucional para sanar as lacunas oriundas do não desenvolvimento presencial de um importante projeto de extensão da IES: o Fema Cidadania.

Nesse sentido, outra ação importante, igualmente relacionada ao projeto Fema Cidadania, foi a adesão do curso de Enfermagem à Campanha Municipal de Vacinação contra a gripe. A Secretaria Municipal de Higiene e Saúde do município criou um Drive-Thru no estacionamento da IES, e alguns professores do curso vacinaram a população-alvo da campanha. A responsabilidade social da instituição se deu, também, quanto às atividades educativas do curso de Enfermagem sobre as medidas de prevenção contra a COVID-19, que aconteceram em escolas públicas do município.

No segundo semestre, as semanas acadêmicas foram realizadas de forma remota pelos cursos de Química, Publicidade e Propaganda, Direito e Ciência da Computação e Análise de Sistemas. Todas foram transmitidas pelo canal oficial da instituição no YouTube, por meio de uma plataforma de streaming para a comunidade escolar e externa. 
A partir do início de outubro, quando o Estado de São Paulo estava a mais de três semanas na fase amarela, as aulas presenciais de Laboratório de Ensino de Química I, II e III retornaram de maneira presencial, obedecendo a um calendário de reposição, que se estendeu até 18 de dezembro, dependendo da carga horária de cada disciplina. Ao retornarem às aulas presenciais, todos os professores e alunos foram submetidos a testes de anticorpos contra a COVID-19, conforme protocolo institucional.

O ano letivo terminou com a aplicação de exames finais de forma remota, respeitando-se todas as normativas expressas no Regimento escolar da IES e com calendário escolar estendido para o curso de Medicina, o qual finalizará o segundo semestre de 2020 no dia 01 de março de 2021.

2.3 As potencialidades e as fragilidades do processo de execução e de consolidação da transposição das aulas presenciais para as aulas em mídias digitais

A habilidade técnica organizacional e o senso de urgência da Direção Acadêmica e Executiva da IES em mobilizar seus colaboradores, a equipe do NEaD no sentido de viabilizar soluções tecnológicas e humanas que promovessem a transposição das aulas presenciais para aulas em mídias digitais, bem como o acolhimento das necessidades sociais dos estudantes, configurou-se, com efeito, numa significativa e considerável potencialidade. Em menos de uma semana, o processo foi desenhado e compartilhado com a comunidade escolar. A equipe do NEaD e os membros dos NDE da instituição trabalharam, exaustivamente, para criar um processo de transição que preservasse os horários de aulas, o calendário acadêmico e os planos de ensino das disciplinas dos cursos, sem deixar de acolher o alunado com todas as suas peculiaridades.

No campo das potencialidades e das fragilidades dos processos remotos de pesquisa e extensão, a manutenção das atividades de pesquisa de forma remota permitiu a continuidade das bolsas de estudo e dos projetos de Iniciação Científica - com adaptações das pesquisas de campo , assim como a realização do Fórum Científico anual atrelado à Semana Nacional de Ciência e Tecnologia do Ministério da Ciência, Tecnologia, Inovações e Comunicações. Os TCCs foram qualificados e defendidos, na modalidade síncrona por meio de plataformas de comunicação, tais como: Google Meet, Microsoft Teams e Zoom.

Apenas um projeto de extensão aconteceu de forma remota, com poucas alterações no desenho original - Projeto Fema Rondon. As ações ocorreram à distância com o apoio da Secretaria de Saúde e de Educação de um munícipio de pequeno porte, localizado a menos de $50 \mathrm{~km}$ da IES. Os outros quatro projetos de extensão da instituição tiveram um desenvolvimento parcial. Isso impactou em diversos processos institucionais, educacionais e sociais e se tornou um grande desafio para o ano de 2021, já que o distanciamento social continuará sendo a medida de prevenção mais eficaz contra a Covid-19 (WHO, 2021). 
O diálogo aberto e franco da equipe diretiva com a comunidade escolar também se constituiu como uma potencialidade frente às Fake News relacionadas ao processo de transposição das aulas para a modalidade remota. A intranet, o WhatsApp institucional e website da instituição sempre foram canais de comunicação amplamente utilizados pela IES.

A presença da modalidade $\mathrm{EaD}$ híbrida na instituição também foi considerada uma potencialidade. A equipe multidisciplinar e o NEaD puderam assessorar e auxiliar os processos instituídos pela equipe diretiva, pelos coordenadores de curso e docentes da Instituição e esclarecer que o processo de transição de aulas presencias para aulas em mídias digitais não significava de mera transposição intermodal, ou seja, uma transposição entre a modalidade presencial e a distância (BRASILEIRO, 2020).

A falta de clareza sobre o conceito de transposição intermodal foi uma fragilidade observada também pelo corpo docente, sobretudo por queles que verbalizavam ressalvas quanto à modalidade a distância. Estudos e reportagens indicam que a modalidade ainda é alvo de descrédito e de desconfiança pela sociedade e por muitos educadores (LITTO, 2011, 2019; RICARDO, 2018; BARBOSA, 2020).

Das fragilidades detectadas durante o processo de execução e de avaliação da transposição das aulas, cumpre ressaltar a capacidade do servidor de internet da IES; a aceitação do Ambiente Virtual de Aprendizagem pelo corpo docente; o conhecimento e o domínio das ferramentas, dos recursos e das atividades de ensino do Moodle pelos docentes e discentes; a necessidade de ampliação do horário de funcionamento dos laboratórios de informática da IES; a disponibilização de profissionais da $\mathrm{TI}$, durante o desenvolvimento das aulas síncronas e de um técnico em informática para prestar serviços junto aos equipamentos computacionais, de instalação e de atualização de programas e softwares, principalmente no que tange aos discentes. Algumas dessas fragilidades foram sanadas; outras, ainda não foram bem compreendidas e aceitas pelos envolvidos nos processos.

Observou-se também que alguns estudantes não possuíam equipamentos computacionais e nem competências técnicas para utilizá-los. Essa observação encontra-se em consonância com os resultados de estudos recentes, inclusive (AZEVEDO et al., 2018; SOUZA et al., 2020). Por outro lado, isso não justifica a ausência de mensuração estatística dessa observação e de outras pela equipe diretiva e do NEaD, tais como: utilização de equipamentos digitais com conexão limitada à internet; uso exclusivo da plataforma Moodle na versão para celular; e ausência de alunos nos laboratórios de informática da instituição. Tratar-se-ia de obstáculos financeiros e arquitetônicos ou de falta de espaço? Seria o respeito ao distanciamento social? Ou a falta de habilidade com a tecnologia (analfabetismo digital)? Muitos seriam os questionamentos a fazer. Mas o fato é que a ampliação do horário de funcionamento dos laboratórios de informática da IES, para atender aos alunos com restrições de cunho tecnológico, não surtiu efeito. Tampouco nenhuma das hipóteses foi corroborada ou refutada. 
$\mathrm{Na}$ tentativa de atender às demandas de uma parcela significativa de alunos que verbalizavam dificuldades em acessar as aulas on-line e as atividades educativas off-line, a equipe diretiva normatizou o prazo de $24 \mathrm{~h}$ para o desenvolvimento de todas as atividades avaliativas, bem como a gravação das videoaulas e a disponibilização imediata do link de acesso da gravação no Moodle. Essa medida foi considerada uma potencialidade pelos estudantes e docentes, apesar de críticas legítimas do corpo docente quanto à eficácia e à validade do processo avaliativo.

Mais uma questão que denotou uma fragilidade refere-se à capacitação docente para adaptação dos conteúdos programáticos e dos métodos de ensino. Os coordenadores de curso atuaram de forma muito próxima com os seus professores e a equipe do NEaD; porém, não houve um questionário objetivo - qualitativo e quantitativo - sobre as competências e as habilidades dos docentes para manejar os planos e aplicar outros métodos de ensino atrelados às reais condições tecnológicas de letramento digital dos docentes, principalmente daqueles graduados antes dos anos 2000. Muito provavelmente esse fato pode ter impactado, de maneira negativa, o processo de ensino e de aprendizagem.

Tem-se, por fim, como uma potencialidade a ciência das fragilidades expostas e a disposição em saná-las em um movimento interprofissional, interdisciplinar e de consciência coletiva em prol do processo educativo e da inclusão digital e acadêmica de todos os alunos.

\section{CONCLUSÃO}

Este relato descreveu a experiência da equipe de um NEaD na participação da concepção e execução do processo de transposição das aulas presenciais para aulas em mídias digitais, em uma IES de um município do Vale do Paranapanema, sob a ótica das fragilidades e das potencialidades que permearam toda essa ação desde março até dezembro de 2020.

Tal processo foi marcado pela urgência imposta pela pandemia do novo coronavírus e pelos efeitos do distanciamento social, que acarretaram sobrecarga emocional e laboral no ensino e aprendizagem, trazendo a necessidade de articulação e de integração de toda a comunidade escolar e de seus processos de trabalho em um movimento de gestão de pessoas sem precedentes na instituição em análise.

A IES passou por uma reorganização de gestão escolar, de ensino e de assistência social. Certamente, essa reestruturação será revista e estará em constante transformação em virtude das demandas da atual conjuntura sobre a sociedade e o ensino.

Uma ação que se faz urgente na IES consiste na busca coletiva por sanar uma fragilidade evidente e exposta neste trabalho: a ausência de investigação científica e de dados estatísticos sobre o fenômeno da substituição das aulas presencias. A promoção e a realização de pesquisas de níveis mais acurados e a concepção e execução de grupos de estudo impõe-se neste momento com vistas à elaboração de um diagnóstico situacional e estratégico de enfrentamento aos problemas 
oriundos dessa nova realidade. Um instrumento de pesquisa que poderia ser aplicado em larga escala pela confiabilidade - ratificado por altas consistências internas, facilidade e rapidez na aplicação e reprodutibilidade, sem reserva de direitos autorais - seria a Escala de Reações Prospectivas aos Estudos a Distância (ERP-ED), de autoria de Souza et al. (2020). Naturalmente que isso seria objeto de outro estudo, que ora se pode vislumbrar.

Acredita-se, sim, que a maior contribuição deste relato foi o compartilhamento de experiências, de ideias, de observações e reflexões de uma prática de gestão escolar e educativa pautada na manutenção do Ensino Superior e em estratégias pedagógicas não convencionais em um momento atípico. Mais do que isso: os momentos exitosos e os marcados pelas fragilidades da IES não são uma peculiaridade desta instituição apenas. O Brasil e o mundo estão tendo que lidar com situações semelhantes às descritas neste relato. Apesar de um ano de muitos desafios, a maioria dos alunos e dos professores permaneceram na empreitada e finalizaram o ano letivo. $\mathrm{A}$ evasão, a inadimplência e as reprovas devido ao não aproveitamento e frequência não foram significativas. A instituição recebeu depoimentos de alunos, relatando já terem se adaptado às novas formas de ensino, embora sentissem saudade das atividades presenciais. Esses mesmos depoimentos foram expressos pelos coordenadores e professores em um movimento de saudosismo e de entusiasmo pelos processos que vivenciaram e que ainda vivenciarão.

\section{REFERÊNCIAS}

ARRUDA, E. P. Reflexões sobre a política nacional de formação de professores a distância e o enfraquecimento da EaD pública pela Universidade Aberta do Brasil (UAB). Universidade Federal de Santa Maria (UFSM). Revista Educação (UFSM), v. 43, n. 4, out./dez. 2018.

AZEVEDO, D. S. et al. Letramento digital: uma reflexão sobre o mito dos "Nativos Digitais". RENOTE - Revista Novas Tecnologias na Educação, v. 16, n. 2, p. 615-625, 2018.

BARBOSA, A. Demanda por EAD ajuda a derrubar preconceitos e impulsionar negócios. 0 Estado de São Paulo, São Paulo, abr. 2020.

BARREIRO, I.M.F.; GEBRAN, R.A. Prática de ensino e estágio supervisionado na formação de professores. São Paulo: Avercamp, 2006.

BELLONI, M.L. Educação a distância. 7. ed. Campinas: Autores Associados, 2015.

BRASIL. Portaria $n^{\circ} 1.428$, de 28 de dezembro de 2018. Dispõe sobre a oferta, por Instituições de Educação Superior - IES, de disciplinas na modalidade a distância em cursos de graduação presencial. Diário Oficial da União, Brasília, Distrito Federal, 31 dez. 2018. Seção I, p. 59. BRASIL. Ministério da Educação. Portaria ${ }^{\circ} 356$, de 11 de março de 2020. Dispõe sobre a regulamentação e operacionalização do disposto na Lei $n^{\circ} 13.979$, de 6 de fevereiro de 2020, que estabelece as medidas para enfrentamento da emergência de saúde pública de importância internacional decorrente do coronavírus (COVID-19). Diário Oficial da União, seção 1, p. 185. Brasília, DF, 12 mar. 2020a. 
BRASIL. Lei n ${ }^{\circ}$ 13.979, de 6 de fevereiro de 2020. Dispõe sobre as medidas para enfrentamento da emergência de saúde pública de importância internacional decorrente do coronavírus responsável pelo surto de 2019. Diário oficial da União, seção 2, edição extra A. Brasília, DF, 07 fev. 2020b.

BRASIL. Ministério da Educação. Portaria n 343, de 17 de março de 2020. Dispõe sobre a substituição das aulas presenciais por aulas em meios digitais enquanto durar a situação de pandemia do Novo Coronavírus - COVID-19. Diário Oficial da União, seção 1, p. 39. Brasília, DF, 18 mar. 2020c.

BRASIL. Ministério da Educação. Portaria ${ }^{\circ} 345$, de 19 de março de 2020. Altera a Portaria MEC $n^{\circ}$ 343, de 17 de março de 2020. Diário Oficial da União, seção 1, p. 1. Brasília, DF, 19 mar. 2020 d.

BRASIL. Ministério da Educação. Portaria n 395, de 15 de abril de 2020. Prorroga o prazo previsto no $\S 1^{\circ}$ do art. $1^{\circ}$ da Portaria $n^{\circ} 343$, de 17 de março de 2020.

Diário Oficial da União, Brasília, DF, 15 abr. 2020e.

BRASIL. Ministério da Educação. Portaria ${ }^{\circ} 473$, de 12 de maio de 2020. Prorroga o prazo previsto no $\S 1^{\circ}$ do art. $1^{\circ}$ da Portaria $n^{\circ} 343$, de 17 de março de 2020. Diário Oficial da União, seção 1, p. 55. Brasília, DF, 13 maio $2020 f$.

BRASIL. Ministério da Educação. Portaria n 544 , de 16 de junho de 2020. Dispõe sobre a substituição das aulas presenciais por aulas em meios digitais, enquanto durar a situação de pandemia do novo coronavírus - Covid-19, e revoga as Portarias $M E C \mathrm{n}^{\circ} 343$, de 17 de março de 2020, n 345, de 19 de março de 2020, e nº 473, de 12 de maio de 2020. Diário Oficial da União, seção 1, p. 60. Brasília, DF, 17 jun. 2020g.

BRASILEIRO, C. Curso de Extensão em Produção de Material Didático para EaD: aula 8 Transposição didática 2: os desafios intermodais. Rio de Janeiro: Universidade Federal Fluminense, 2020. [17] p.

CHRISTIANSEN, M. A. Inverted Teaching: applying a new pedagogy to a university organic Chemistry class. Journal of Chemical Education, v. 11, n. 91, p. 1845-1850, 2014.

CONSELHO ESTADUAL DE EDUCAÇÃO. Deliberação CEE 177/2020. Fixa normas quanto à reorganização dos calendários escolares, devido ao surto global do Coronavírus, para o Sistema de Ensino do Estado de São Paulo, e dá outras providências. Diário Oficial do Estado de São Paulo, seção I, v. 130. São Paulo, SP, 16 abr. 2020a.

CONSELHO ESTADUAL DE EDUCAÇÃO. Deliberação CEE 109/2020. Dispõe sobre orientações para Instituições de Ensino Superior, vinculadas ao Sistema de Ensino do Estado de São Paulo, devido ao surto global da Covid-19. Diário Oficial do Estado de São Paulo, seção I, v. 130. São Paulo, SP, 16 abr. 2020b.

CONSELHO ESTADUAL DE EDUCAÇÃO. Deliberação CEE 185/2020. Fixa procedimentos para o cumprimento da carga horária de estágio, atividades práticas, atividades laboratoriais e de internato visando a continuidade e conclusão dos cursos da área da saúde nas Instituições de Ensino Superior, vinculadas ao Sistema de Ensino do Estado de São Paulo, tendo em vista o surto global da Covid-19, e dá outras providências. Diário Oficial do Estado de São Paulo, seção I, p. 213. São Paulo, SP, 17 jul. 2020c. 
DIAS, É.; PINTO, F.C.F. A Educação e a Covid-19. Ensaio: aval. pol. públ. Educ., Rio de Janeiro, v. 28, n. 108, p. 545-554, set. 2020.

FUNDAÇÃO EDUCACIONAL DO MUNICÍPIO DE ASSIS. Instituto Municipal de Ensino Superior de Assis (IMESA), Campus José Santilli Sobrinho. Portaria $\mathbf{n}^{\circ}$ 43, de 01 de outubro de 2018. Nomeia e constitui equipe multidisciplinar responsável pelo acompanhamento e aprovação do material didático produzido na modalidade E.A.D - Ensino à Distância. Assis: IMESA, 2018.

FUNDAÇÃO EDUCACIONAL DO MUNÍCÍPIO DE ASSIS. Direito tem aprovação recorde na OAB. Assis, SP: FUNDAÇÃO EDUCACIONAL DO MUNÍCÍPIO DE ASSIS, 2020. Disponível em: http://fema.edu.br/index.php/noticias-pagina/1835-direito-tem-aprovacao-recorde-na-oab. Acesso em: 10 jan. 2021.

LAHAM, S.A.D; CONSTANTINO, G.M.S. REGRAS DE NETIQUETA PARA REUNIÕES E AULAS ON-LINE. Assis: Fundação Educacional do Município de Assis, 2020.

LITTO, F. M. Infrações que prejudicam a imagem da EaD!. In: LITTO, F.M.; FORMIGA, M. (Org.). Educação a Distância - O Estado da Arte - volume 2. 1. ed. São Paulo: Pearson, 2011, v. 2, p. 367373.

LITTO, F. M. Explorando a Variedade de Estratégias Ativas na EAD. In: $25^{\circ}$ CONGRESSO INTERNACIONAL ABED DE EDUCAÇÃO A DISTÂNCIA, 2019, Poços de Caldas.

MOREIRA, A.J.; SCHLEMMER, E. Por um novo conceito e paradigma de educação digital onlife. Revista UFG, v. 20, n. 26, maio. 2020.

MOORE, M. G. Teoria da Distância Transacional. In: KEEGAN, D. Theoretical Principles of Distance Education. Tradução de Wilson de Azevedo, revisão de tradução de José Manuel da Silva. Revista Brasileira de Aprendizagem Aberta e a Distância, São Paulo, v.1, ago. 2002. (Tradução de: Theoretical Principles of Distance Education).

NASCIMENTO, D. F. Implicações do Modelo Institucional da UAB na Gestão De Cursos a Distância ao Âmbito da UFPE. ESUD - Congresso Brasileiro de Ensino Superior a Distância. Florianópolis, 2014.

PINHO, A. Menos de metade dos alunos da rede estadual de SP acessa ensino online na quarentena. Folha de São Paulo, São Paulo, maio. 2020.

RICARDO, J.S. Quebrando paradigmas: do preconceito à realidade da educação a distância. Revista Científica de Educação a Distância, Ribeirão Preto, v.10, n. 18, jul. 2018.

SÃO PAULO. Decreto $n^{\circ}$ 64.862, de 13 de março de 2020. Dispõe sobre a adoção, no âmbito da Administração Pública direta e indireta, de medidas temporárias e emergenciais de prevenção de contágio pelo COVID-19 (Novo Coronavírus), bem como sobre recomendações no setor privado estadual. Diário Oficial do Estado de São Paulo, seção I, v. 130, n. 51. São Paulo, SP, 14 mar. 2020.

SILVA, A.J. F. et al. A adesão dos alunos às atividades remotas durante a pandemia: realidades da educação física escolar. Corpoconsciência, Cuiabá, v. 24, n. 2, p. 57-70, mai./ ago., 2020.

SOUZA G. H. S. de et al. Reações Prospectivas de Estudantes frente aos Estudos Remotos durante a Pandemia da Covid-19. Rev. Bras. Aprend. Aberta, São Paulo, v. 19, n. 1, 2020. 
SUÁREZ, D.H. Relatos de experiencia, saber pedagógico y reconstrucción de la memoria escolar. Educ. rev., Belo Horizonte, v. 27, n. 1, abr. 2011.

ZABALZA, M. Diários de Aula - Um Instrumento de Pesquisa e Desenvolvimento Profissional. Porto Alegre: Artmed, 2009.

WORLD HEALTH ORGANIZATION (WHO). Press Conference. [Geneva]: Word Health Organization, 2021. (1h09min07s). Disponível em: https://www.who.int/emergencies/diseases/novelcoronavirus-2019. Acesso em: 26 jan. 2021. 